\title{
Dementia in advanced age led to higher mortality rates and shortened life
}

Agüero-Torres H, Fratiglioni $L$, Guo Z, et al. Mortality from dementia in advanced age: a 5-year follow-up study of incident dementia cases.J Clin Epidemiol 1999 Aug;52:737-43.

QUESTION: What is the mortality rate and survival time for patients with dementia in advanced age, and does this rate vary by sex and age?

\section{Design}

Inception cohort followed up for 5 years.

\section{Setting}

Community based study in Stockholm, Sweden.

\section{Patients}

127 patients ( $65 \% \geqslant 85$ y of age, $87 \%$ women) with clinically definite dementia using DSM-III-R criteria; $80 \%$ had Alzheimer's disease (AD), 17\% had vascular dementia, and 3\% were classified as having other dementias. A comparison group of 790 non-demented people $(61 \%$ between 77 and 84 y of age, $75 \%$ women) were also followed.

\section{Assessment of prognostic factors}

At baseline, data on family and personal history were collected and psychological tests were administered. A diagnosis of dementia was made using DSM-III-R criteria.

\section{Main outcome measures}

Mortality rate and survival time.

\section{Main results}

After 5 years, $70 \%$ of patients with dementia had died compared with $35 \%$ of those without dementia. After controlling for sociodemographic variables and comorbidity, $14 \%$ of all deaths could be attributed to dementia with a risk of death among patients with dementia twice as high as that for non-demented people. The mean survival time was 3.0 years (CI 2.7 to 3.4) for patients with dementia and 4.2 years (CI 4.1 to 4.3 ) for those without dementia. The specific mortality rate for all dementias was 2.4 per 100 person years (95\% CI 1.9 to 3.0) and 1.9 per 100 person years (CI 1.5 to 2.4) for those with $\mathrm{AD}$. The relative risk of death was 2.0 (CI 1.5 to 2.7) for $\mathrm{AD}$ and 3.3 (CI 2.0 to 5.3) for vascular dementia. Age and sex specific mortality rates, relative risk of death, and population attributable risk of death are shown in the table.

\section{Conclusions}

Compared with non-demented people, patients with dementia had higher mortality rates and a shortened survival time. The population attributable risk of death associated with dementia was higher in women (in both age groups; $77-84 \mathrm{y}$ and $\geqslant 85 \mathrm{y}$ ) than in men.

\section{COMMENTARY}

The proportion of elderly people in the population is growing in most western countries and dementia is a common disorder in this age group. Surprisingly, however, we have limited knowledge of its natural history and prognosis. Most studies on mortality associated with dementia until now have relied on death certificates to estimate the mortality of dementia, examined prevalent cases, or used selected populations. Death certificates significantly under-report dementia and using prevalent cases or mortality in selected populations is not very useful for most clinicians. This study by Agüero-Torres et al is important because it followed up newly diagnosed (incident) cases of dementia from a well defined community in Sweden.

For clinicians, patients, and carers the usefulness of this study is straightforward. Faced with a newly diagnosed patient with dementia over the age of 77 years, clinicians can now say that the patient's mortality risk is about twice that of a non-demented person and the average survival time is about 3 years. The effect of dementia on mortality is greater if your patient is female and younger (between 77 and $84 y$ of age) although these findings were based on a small number of deaths and are therefore of uncertain reliability. Why there is an increase in mortality is unclear. It could be caused by the disease process itself or because the higher risk people with dementia have for other causes of death such as falls or poor nutrition.

What is needed now are similar studies for the "younger elderly" and investigation of factors which affect the prognosis.

Simon Hatcher, BSc, MBBS, MMedSc University of Auckland Auckland, New Zealand

Mortality rates by age and sex; relative risk (RR) of death comparing those with and without dementia; and population attributable risk (PAR) of death

\begin{tabular}{cllll} 
& \multicolumn{2}{l}{ Mortality rate per $\mathbf{1 0 0}$ person (95\% Cl) } & & \\
\cline { 2 - 4 } $\begin{array}{l}\text { Age } \\
\text { group }(y)\end{array}$ & $\begin{array}{l}\text { Patients with } \\
\text { dementia }\end{array}$ & $\begin{array}{l}\text { Patients without } \\
\text { dementia }\end{array}$ & RR (Cl) & PAR (Cl) \\
\cline { 1 - 4 } Men & & & & \\
\hline $77-84$ & $28.8(9.2$ to 67.3$)$ & $8.1(5.5$ to 11.1$)$ & $3.6(1.4$ to 9.1$)$ & $10 \%(8$ to 13$)$ \\
\hline$\geqslant 85$ & $24.8(10.8$ to 48.9$)$ & $14.6(11.2$ to 18.7$)$ & $1.7(0.8$ to 3.5$)$ & $5 \%(4$ to 7$)$ \\
\hline Women & & & & \\
\hline $77-84$ & $17.5(8.4$ to 32.3$)$ & $3.9(2.8$ to 5.3$)$ & $4.5(2.2$ to 8.9$)$ & $17 \%(13$ to 20$)$ \\
\hline$\geqslant 85$ & $23.6(18.2$ to 30.0$)$ & $10.0(8.4$ to 11.8$)$ & $2.4(1.8$ to 3.2$)$ & $18 \%(14$ to 20$)$ \\
\hline Total & $23.0(18.5$ to 28.3$)$ & $8.5(7.5$ to 9.5$)$ & $2.7(2.1$ to 3.4$)$ & $15 \%(12$ to 15$)$ \\
\hline & & & &
\end{tabular}

